\title{
Multi-criteria multi-stakeholder decision analysis using a fuzzy- stochastic approach for hydrosystem management
}

\author{
YOHANNES H. SUBAGADIS, NIELS SCHÜTZE \& JENS GRUNDMANN \\ Technische Universität Dresden, Institute of Hydrology and Meteorology, 01069 Dresden, Germany \\ yohannes.subagadis@mailbox.tu-dresden.de
}

\begin{abstract}
The conventional methods used to solve multi-criteria multi-stakeholder problems are less strongly formulated, as they normally incorporate only homogeneous information at a time and suggest aggregating objectives of different decision-makers avoiding water-society interactions. In this contribution, MultiCriteria Group Decision Analysis (MCGDA) using a fuzzy-stochastic approach has been proposed to rank a set of alternatives in water management decisions incorporating heterogeneous information under uncertainty. The decision making framework takes hydrologically, environmentally, and socio-economically motivated conflicting objectives into consideration. The criteria related to the performance of the physical system are optimized using multi-criteria simulation-based optimization, and fuzzy linguistic quantifiers have been used to evaluate subjective criteria and to assess stakeholders' degree of optimism. The proposed methodology is applied to find effective and robust intervention strategies for the management of a coastal hydrosystem affected by saltwater intrusion due to excessive groundwater extraction for irrigated agriculture and municipal use. Preliminary results show that the MCGDA based on a fuzzy-stochastic approach gives useful support for robust decision-making and is sensitive to the decision makers' degree of optimism.
\end{abstract}

Key words multi-criteria decision analysis; fuzzy-stochastic approach; coastal hydrosystem management

\section{INTRODUCTION}

In many real-world water resources management problems, the decision-making process is generally complex and faced with multiple criteria related to the physical environment and socioeconomics to consider. This makes the problem a multi-criteria (or multi-objective) decision problem for which one single solution is not readily available due to the existing trade-offs among conflicting quantitative and qualitative objectives. In addition, the water resources management decision-making process and its final outcomes are affected by the inputs and perceptions of different parties involved in the process, which also leads to a problem of multiple stakeholders or a multi-decision maker problem.

Many Multi-Criteria Decision Making (MCDM) techniques conventionally used in the literature to solve real-world water resources management problem give unsatisfactory solutions (Raju et al. 2000, Xu and Tung 2009) for the following reasons: (i) they normally incorporate only homogeneous information (either numerical or linguistic variables) and do not deal with heterogeneous information simultaneously, and (ii) different types of uncertainty (subjective and objective) of different alternatives are not considered at the same time. In recent years, there has been limited efforts to incorporate different types of uncertainty in multi-criteria decision-making (Chou et al. 2008, Xu and Tung 2009, Zarghami and Szidarovszky 2009, Mousavi et al. 2013). However, there are still limitations when different types of uncertainty are incorporated into multi-criteria decision-making based on heterogeneous information. In addition, applications of these techniques, which also consider water-society interactions in real-world water resources management, are rare.

\section{Study area and decision problem}

The feasibility of MCGDA using a fuzzy-stochastic approach is tested in a real-world hydrosystem assuming group decision-making under uncertainty. The water management problem of this study refers to a coastal agricultural region in an arid environment and is adapted to the specific situation of the Al-Batinah region in northern Oman. Enduring overexploitation of the aquifer has caused the intrusion of marine salt water from the sea. Consequently, shallow wells of small farms and households run dry and/or irrigation water becomes increasingly saline - which has enforced numerous people to abandon their farms, thereby endangering the traditional socio-economic structures and way of living (Al-Shaqsi 2004, Grundmann et al. 2012). 
Therefore, the goal of this study is to look for best management strategies that would help to respond to the current unbalanced relationship between water resources availability and water demand in this coastal region. The management alternatives and evaluation criteria were determined based on: (1) an integrated simulation-based water management model which accounts for the interaction of physical processes of a strongly coupled groundwater-agriculture hydrosystem, and (2) expert knowledge and literature review. Considering the availability of data and the integrated simulation-based optimization model development situations at the stage of this research, three management alternatives (A1, A2 and A3) and five criteria $(\mathrm{C} 1, \mathrm{C} 2, \mathrm{C} 3, \mathrm{C} 4$ and C5) are considered here, as illustrated in Table 1.

\section{METHODS}

In response to the aforementioned decision problem, this paper presents a new methodological framework for combining objective and subjective criteria in a decision-making procedure, and the

Table 1 Criteria and alternatives developed to address the decision problem.

\begin{tabular}{lll}
\hline Alternatives & Criterion & \\
\hline $\begin{array}{l}\text { A1: Hydrosystem sustainability oriented: } \\
\text { under this value range an intended increase } \\
\text { in hydrosystem stability comes with higher } \\
\text { agricultural profit risk }\end{array}$ & Economic factors & $\begin{array}{l}\text { C1:Profitability of crops (annual } \\
\text { economic profit) } \\
\text { C2:Cost of irrigation (pumping, } \\
\text { variable and fixed costs) }\end{array}$ \\
$\begin{array}{l}\text { A2:Multi-obiective: The stakeholders } \\
\text { (farmers) pay same attention for both } \\
\text { aquifer sustainability and agricultural profit }\end{array}$ & $\begin{array}{l}\text { Environmental } \\
\text { factors }\end{array}$ & $\begin{array}{l}\text { C3:Pumped water quantity } \\
\text { (discharge) }\end{array}$ \\
$\begin{array}{l}\text { A3:Agricultural profit oriented: under this } \\
\text { scenario, an increase of the agricultural } \\
\text { production vield comes with high risk of } \\
\text { hydrosystem sustainability }\end{array}$ & Social factors & $\begin{array}{l}\text { C5:Job creation (employment of rural } \\
\text { labour) }\end{array}$ \\
\hline
\end{tabular}

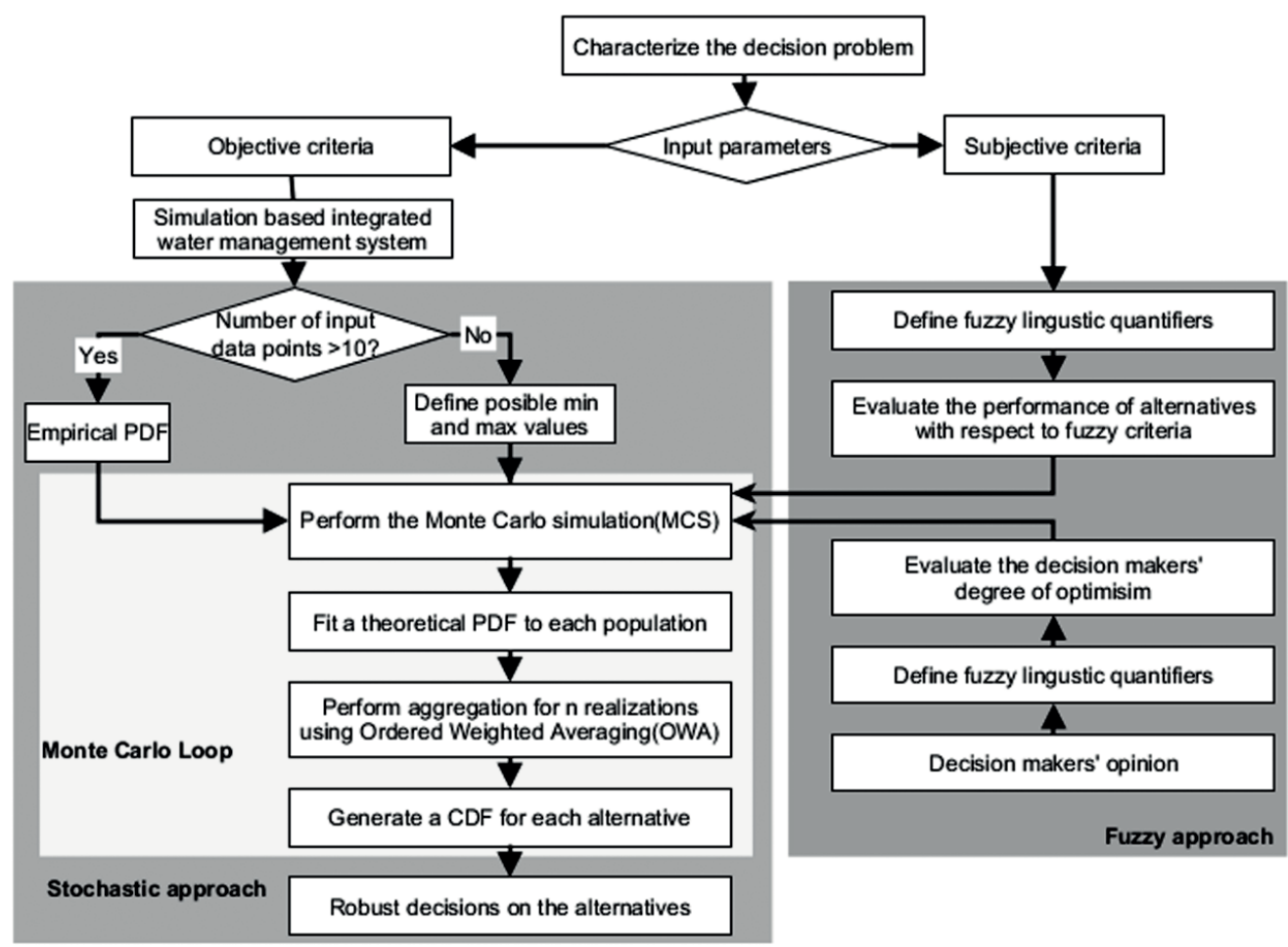

Fig. 1 Flow chart of the multi-criteria multi-stakeholder decision analysis using a fuzzy-stochastic approach. 
evaluation of the related uncertainties in water resources management. A fuzzy-stochastic approach is developed to demonstrate how the approach can effectively be used to prioritize different management alternatives under different types of uncertainty (subjective/objective) and information (qualitative/quantitative). A schematic of the proposed methodology is shown as a flow chart in Fig. 1.

The first step of the proposed approach involves evaluating the performance of alternatives with respect to the different types of criteria. The ratings of alternatives with respect to objective and subjective criteria are evaluated by simulation-based optimization and fuzzy linguistic quantifiers, respectively. The model results and experts' linguistic assessments are aggregated to approximate a series of probability distributions for randomized alternatives with respect to the criteria. Monte Carlo simulation is then used to generate a random normalized decision matrix of probability distribution functions which standardizes different types of criteria with respect to uncertainty (subjective/objective) and information (qualitative/quantitative). Thereafter, the optimism degree of decision makers is calculated and the cumulative distribution function (CDF) for each alternative (using OWA operator to calculate the total performance of each alternative) is produced. Finally, management alternatives are ranked based on the corresponding CDF of the alternatives (Fig. 1).

\section{Ordered Weighted Averaging (OWA) operator}

The total performance value for each alternative under a stochastic environment is calculated using the OWA operator. OWA as an aggregation operator was initiated by Yager (1988) and since then has been applied extensively. The range of OWA between possible minimum and maximum value can be expressed through the orness degree (optimism degree) and it depends on the optimism degree of Decision Makers (DMs). In this paper the fuzzy quantifiers of the form as shown in Table 2 are used in questioning the group of DMs (see Fig. 1).

Table 2 Relations between fuzzy numbers and linguistic quantifiers for optimism degree evaluations.

\begin{tabular}{lll}
\hline Linguistic variables & Triangular fuzzy numbers & Optimistic condition \\
\hline Very low $(\mathrm{VL})$ & $(0,0.0 .3)$ & Very pessimistic \\
Low $(\mathrm{L})$ & $(0,0.3,0.5)$ & Pessimistic \\
Medium $(\mathrm{M})$ & $(0.2,0.5,0.8)$ & Neutral \\
High $(\mathrm{H})$ & $(0.5,0.7,1)$ & Optimistic \\
Very high $(\mathrm{VH})$ & $(0.7,1,1)$ & Very optimistic \\
\hline
\end{tabular}

The total performance measure of each alternative using OWA is calculated using equation (1) as it is derived by Yager (1996):

$$
F=\sum_{j=1}^{n}\left[\left(\frac{j}{n}\right)^{\frac{1}{\theta}-1}-\left(\frac{j-1}{n}\right)^{\frac{1}{\theta}-1}\right] * b_{j}
$$

where, $F=$ total performance measure of an alternative, $b_{j}$ is the $j$ th largest element in the input set, $\theta$ is the optimism degree quantified by DMs, and $n$ stands for a number of input parameters. An alternative with highest total values is considered to be most satisfying alternative. This calculation is repeated for number of MCS realizations and the CDF describing the overall performance of each alternative was developed. The CDF's shape and magnitude of the total performance of the alternatives generated through MCS depend on the optimism degree of the DMs, as well as subjective and objective criteria (see equation (1)).

\section{DATA ACQUISITION}

\section{Simulation-based water management model}

For simulating the interacting physical processes of a strongly coupled groundwater-agriculture hydrosystem in arid coastal environments, a simulation-based optimization model was developed 
by Grundmann et al. $(2012,2013)$. The optimization model, which is based on multi-criteria evolutionary optimization techniques, connects simulation models describing the interaction of the groundwater system and the agricultural production, and is used for managing both water quality and water quantity. The optimization problem is of multi-objective type and considers a sustainability index (SI) and profit of agricultural production as objectives. The SI describes the stability of the hydrosystem evaluating the change of the aquifer state in a simulation period using average salinity concentrations and aquifer water levels (Grundmann et al. 2013).

The results of the multi-criteria optimization (Pareto-optimal solutions) are presented in Fig. 2. The Pareto optimal solutions were divided into three clusters (A1, A2 and A3) based on the shape of the Pareto front, using the subtractive clustering technique (Chiu 1994). The clusters represent specific classes of optimal solutions assuming that certain weights are assigned to the single objectives. Accordingly, in this study the three clusters (A1, A2, and A3) represent different management alternatives (see Table 1 for the description of management alternatives).

\section{Expert knowledge}

For performance evaluation of management alternatives with respect to subjective criteria and to quantify decision makers' judgment and opinion about the decision problem, necessary information is obtained from expert knowledge (Fig. 1).

Therefore, a linguistic judgment is obtained from experts through questionnaires, expert panels, and survey. In this study, five triangular fuzzy numbers are used to represent linguistic terms with the expectation that experts will feel more comfortable using linguistic terms instead of crisp numbers to express their opinion and evaluate management alternatives.

(a)

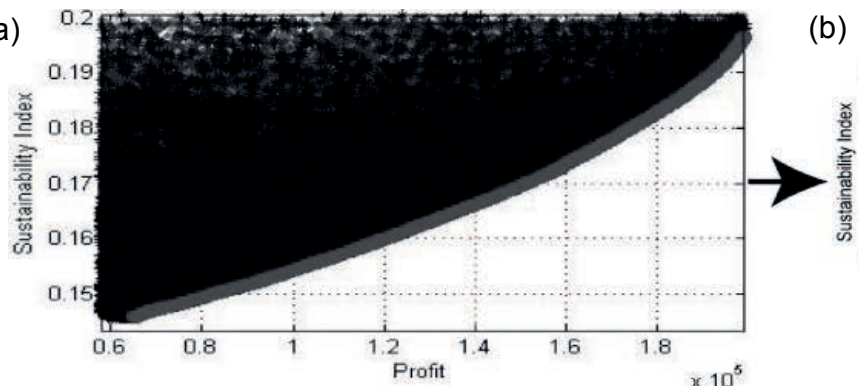

(b)

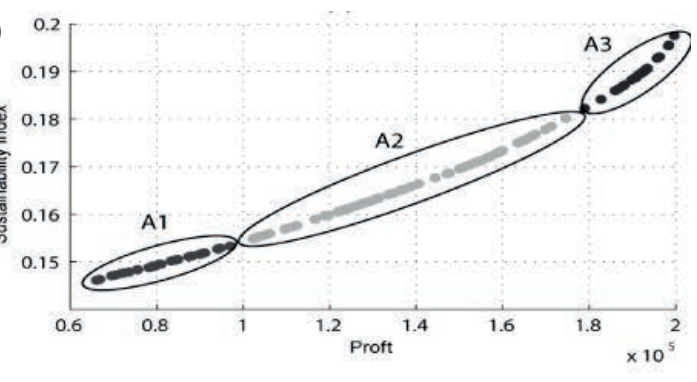

Fig. 2 (a) Pareto solutions for the objective functions "Sustainability index" and "profit (\$/year)", (b) derived cluster visualization (A1, A2, and A3) on the Pareto front.

Table 3 Expert assessment for evaluating alternatives with respect to subjective criteria using linguistic variables.

\begin{tabular}{lllll}
\hline Alternatives & \multicolumn{2}{l}{ Criterion $(\mathrm{C} 5)$} & & \\
& $\mathrm{DM}_{1}$ & $\mathrm{DM}_{2}$ & $\mathrm{DM}_{3}$ & Aggregated \\
\hline A1 & $\mathrm{L}$ & $\mathrm{VL}$ & $\mathrm{L}$ & $(0,0,5)$ \\
$\mathrm{A} 2$ & $\mathrm{M}$ & $\mathrm{L}$ & $\mathrm{H}$ & $(0,4.7177,10)$ \\
A3 & $\mathrm{VH}$ & $\mathrm{H}$ & $\mathrm{M}$ & $(2,7.0473,10)$ \\
\hline
\end{tabular}

The linguistic assessment for alternatives with respect to the subjective criteria (C5) and the optimism degree $(\theta)$ of decision makers' have been provided by three experts $\left(\mathrm{DM}_{1}-\mathrm{DM}_{2}\right)$. They were asked to rate the performance of each alternative with respect to C5 and optimism degree $(\theta)$ using a linguistic scale. Tables 3 and 4 summarise the linguistic assessment made by individual experts, as well as the aggregated values. To incorporate this qualitative and subjective information in the decision making process, the assessments have been aggregated such that triangular fuzzy distributions can be estimated in order to generate random triangular fuzzy numbers. The most possible, lower and upper bound values of a triangular fuzzy number are calculated using the geometric mean technique. 
Table 4 Evaluation of optimism degree $(\theta)$ using linguistic variables.

\begin{tabular}{llll}
\hline Optimism degree $(\theta)$ & $\begin{array}{l}\text { Decision makers } \\
\mathrm{DM}_{1}\end{array}$ & $\mathrm{DM}_{2}$ & $\mathrm{DM}_{3}$ \\
\hline Linguistic variables & $\mathrm{M}$ & $\mathrm{H}$ & $\mathrm{H}$ \\
Triangular fuzzy numbers & $(0.2,0.5,0.8)$ & $(0.5,0.7,1)$ & $(0.5,0.7,1)$ \\
Aggregated group fuzzy value & $(0.2,0.62573,1)$ & & \\
\hline
\end{tabular}

\section{RESULTS}

The results and statistics have been obtained by following the proposed MCGDA fuzzy-stochastic approach (Fig. 1). Once the probability distributions of the input parameters are determined, MCSs are performed to generate random values for all input parameters. After performing MCSs, 15 PDFs are obtained and theoretical statistical distribution models are fitted to the empirical PDFs. Figure 3 shows exemplary simulated input decision matrix values. Similar calculations were calculated for the alternatives with respect to all criteria. These simulated values are then used as inputs for the OWA operator, which serves as an aggregation tool to compute the total performance of each alternative.

The calculation is repeated for a number of realizations considering a fixed optimism degree value at a time. As the result, a final CDF is obtained. The CDF of the three alternatives (A1, A2, and A3) considering an optimism degree of 0.5 are shown in Fig. 4.

The output of the result provides the DMs with a range of possible values that each alternative may attain. In addition, the results can help to prioritise between alternatives showing how much one alternative can be better over the other. For example, the possible total value of alternative A3 ranges from 12.2 to 18.3. In contrast to the deterministic approach, the proposed approach enables the decision makers to examine the complete variability of possible outcomes for each alternative. Based on the results of the generated CDFs for the particular optimism degree, the alternatives are ranked as A3 > A2 > A1 (Fig. 4).
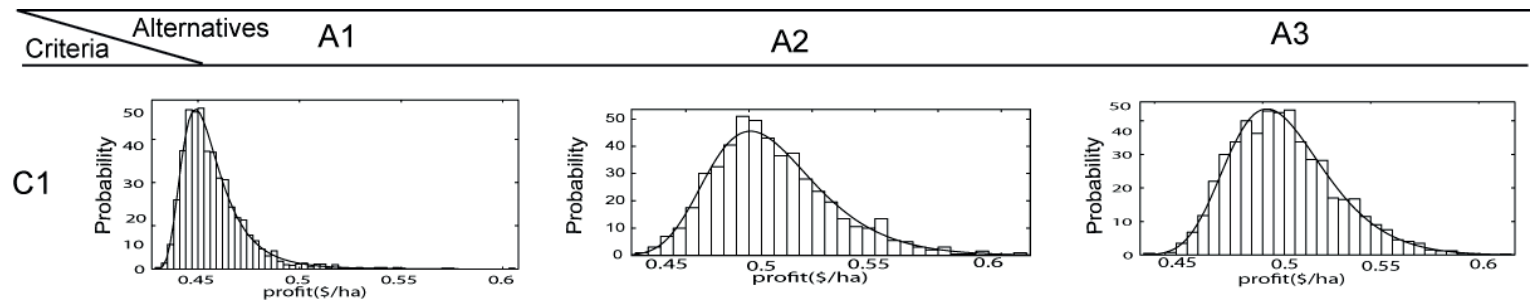

Fig. 3 The decision matrix values - histogram and fitted probability distribution

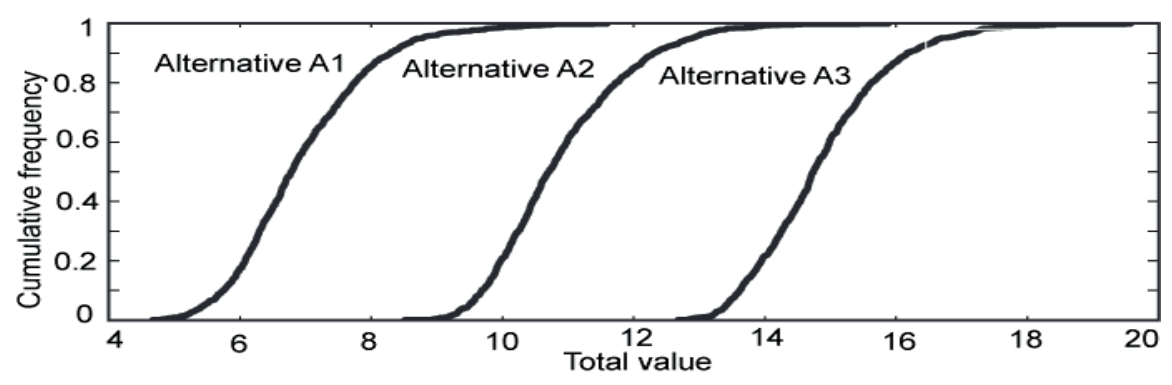

Fig. 4 Cumulative distribution functions (CDFs) generated using OWA operator for the optimism degree of 0.5 , for alternatives $\mathrm{A} 1, \mathrm{~A} 2$, and $\mathrm{A} 3$.

\section{Sensitivity analysis}

The resulting CDF in the previous section are based on a single optimism degree value at a time. To evaluate results of total performance values of the alternatives under different optimism degrees, a sensitivity analysis is conducted. The exemplary results of the sensitivity analysis are displayed in Fig. 5 for alternative A2. The results show that there is a significant variation in the 
total performance values of the alternative depending on the optimism degree. With an increase in optimism degree the total performance values decrease indicating the extent of risk-taking of decision makers. The illustrated sensitivity analysis is important as it shows that the interactive effect of DMs being risk-taking or risk-averse, can influence the final prioritization of management alternatives (Fig. 5).

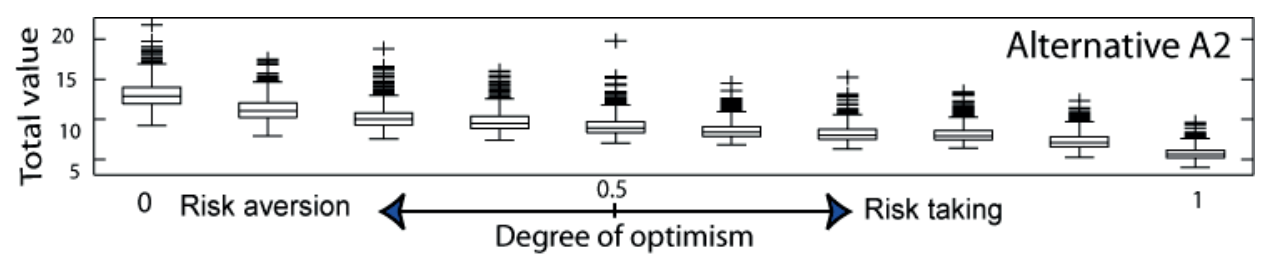

Fig. 5 The MCS sensitivity analysis for various optimism degrees $(\theta)$, on the total performance values of the alternatives (A1, A2 and A3).

\section{CONCLUSIONS}

In this contribution an effective MCGDA using a fuzzy-stochastic approach was proposed. The results shows that the MCGDA using a fuzzy-stochastic approach gives insights that those decisions are sensitive to DMs' degree of optimism. This implies societal actions are conditioning the hydrosystem. Thus, it is important to further develop modelling techniques that can strengthen the interaction between water and society and to provide stakeholders with tools to prioritise alternative management strategies for sustainable development.

\section{REFERENCES}

Al-Shaqsi, S. (2004) The socio economic and cultural aspects in the implementation of water demand management, a case study in the Sultanate of Oman. Department of Geography, University of Nottingham.

Chiu, S. L. (1994) Fuzzy model identification based on cluster estimation. Journal on Intelligent Fuzzy Systems 2, $267-278$.

Chou, S.-Y., Chang, Y.-H. and Shen, C.-Y. (2008) A fuzzy simple additive weighting system under group decision-making for facility location selection with objective/subjective attributes. European Journal of Operational Research 189(1), 132145 .

Grundmann, J., Schuetze, N., and Lennartz, F. (2013) Sustainable management of a coupled groundwater-agriculture hydrosystem using multi-criteria simulation based optimisation. Water Science and Technology 67(3), 689-698.

Grundmann, J., et al. (2012) Towards an integrated arid zone water management using simulation-based optimisation. Environmental Earth Sciences 65(5), 1381-1394.

Mousavi, S. M., Jolai, F. and Tavakkoli-Moghaddam, R. (2013) A Fuzzy Stochastic Multi-Attribute Group Decision-Making Approach for Selection Problems. Group Decision and Negotiation 22(2), 207-233.

Raju, K. S., Duckstein, L. and Arondel, C. (2000) Multicriterion analysis for sustainable water resources planning: a case study in Spain. Water Resources Management 14(6), 435-456.

$\mathrm{Xu}, \mathrm{Y}$. and Tung, Y. (2009) Decision rules for water resources management under uncertainty. J. Water Resour. Plann. Manage. 135(3), 149-159.

Yager, R. R. (1988) On ordered weighted averaging aggregation operators in multi criteria decision making. IEEE Trans Syst Man cybern (18), 183-190.

Yager, R. R. (1996) Quantifier guided aggregation using OWA operators. Int. J. Intell Syst. 11, 49-73.

Zarghami, M. \& Szidarovszky, F.(2009) Stochastic-fuzzy multi criteria decision making for robust water resources management. Stochastic Environmental Research and Risk Assessment 23(3), 329-339. 